\title{
Compressive loading experiment of non-roasted bulk oil palm kernels at varying pressing factors**
}

\author{
Abraham Kabutey ${ }^{1}$, David Herak ${ }^{1}$, Cestmir Mizera ${ }^{1}$, and Petr Hrabe ${ }^{2}$ \\ ${ }^{1}$ Department of Mechanical Engineering, ${ }^{2}$ Department of Material Sciences and Manufacturing Technology, \\ Czech University of Life Sciences Prague, Kamycka 129, Prague, Czech Republic \\ Received November 4, 2017; accepted April 18, 2018
}

\begin{abstract}
A bstract. Compression testing of non-roasted bulk oil palm kernels at different processing factors was performed using a universal compression testing machine and a pressing vessel with a plunger. The purpose of the research was to describe regression models of deformation, deformation energy and percentage kernel oil depending on force, speed and vessel diameter. The tested compression forces were 100, 125, 150, 175 and $200 \mathrm{kN}$, while the speeds were $5,10,15,20$ and $25 \mathrm{~mm} \mathrm{~min}^{-1}$. Three pressing vessels of diameter 60, 80 and $100 \mathrm{~mm}$ were used. Samples were compressed at an initial height of $60 \mathrm{~mm}$. For varying forces and vessel diameters at a constant speed of $5 \mathrm{~mm} \mathrm{~min}^{-1}$, the values of deformation, deformation energy and percentage kernel oil ranged from $28.47 \pm 0.89$ to $37.45 \pm 0.11 \mathrm{~mm}, 796 \pm 0.82$ to $1795 \pm 49.01 \mathrm{~J}$ and $7.33 \pm 0.26$ to $25.67 \pm 0.39 \%$. At a constant force of $200 \mathrm{kN}$ for different speeds and vessel diameters; the aforementioned determined parameters also ranged from $31.91 \pm 1.61$ to $37.63 \pm 1.21 \mathrm{~mm}, 1012 \pm 26.76$ to $1795 \pm 49.01 \mathrm{~J}$ and $14.66 \pm 0.42$ to $24.98 \pm 1.37 \%$. The results were statistically significant $(\mathrm{p}<0.05)$ or (F-ratio $>$ F-critical), with high coefficients of determination between 0.74 and 0.99 . Thus, higher force at specific speed may be needed to maximally recover kernel oil.

Keywords: non-roasted oil palm kernels, linear compression, vessel diameters, mechanical properties, regression equations
\end{abstract}

\section{INTRODUCTION}

In-depth knowledge of mechanical properties such as rupture force, deformation at rupture point, deformation ratio at rupture point, energy for rupture, volume energy or toughness and hardness of bulk oilseeds/kernels is essential for designing ultra efficient oil processing technology (Aripin et al., 2012; Galedar et al., 2009; Ozumba and Obiakor, 2011). These properties are influenced by several

*Corresponding author e-mail: kabutey@tf.czu.cz

**This work was financially supported by the Internal Grant of Faculty of Engineering, CULS Prague, IGA 2017: 31130/ 1312/3111 (2017). factors, including force, speed, moisture content, temperature, pressing vessel diameter, varieties of bulk oilseeds or kernels, among others (Deli et al., 2011, Herak et al., 2010).

The rupture force is the minimum force required to break the bulk material. This is a key factor influencing the energy demand of vegetable oil extraction, and determining the optimal force would enhance the oil recovery efficiency by minimizing the energy input (Akinoso and Raji, 2011; Herak et al., 2010; Raji and Favier, 2004). Deformation at rupture point is the deformation at loading direction and is useful for determining the gap size between the surfaces needed for efficiently compressing the kernels for dehulling or shelling. Energy for rupture is the energy required to rupture the bulk material, and can be ascertained from the area under the rupture force and deformation at rupture point. Toughness is the ratio of rupture energy to that of the volume of sample. It is actually the work required to cause a rupture of the bulk material and can be approximated by the area under the force-deformation curve up to the rupture point. Hardness is the ratio of rupture force and deformation at rupture point (Galedar et al., 2009; Karaj and Muller, 2010; Sirisomboon et al., 2007).

The available literature on the compression loading of bulk oil palm kernels mainly evaluated the rupture force, deformation, energy and toughness of a single kernel or seed dependent on temperature, moisture content and loading position (Akinoso and Raji, 2011; Ozumba and Obiakor, 2011). In terms of oil recovery efficiency and energy utilization, the compression of bulk oil material is economically viable compared to a single kernel or seed under compression loading (Karaj and Muller, 2011; Tunde-Akintunde

(C) 2018 Institute of Agrophysics, Polish Academy of Sciences 
et al., 2001; Zheng et al., 2003). In view of that, our previously published studies focused on the mechanical behaviour of bulk oilseeds or kernels of rapeseeds, sunflower seeds, jatropha seeds and oil palm kernels in compression loading where the pressing factors such as force, speed and vessel diameter remained constant variables (Divišová et al., 2014; Herak et al., 2012, 2013; Kabutey et al., 2013, 2015; Sigalingging et al., 2014, 2015). Compression loading involves a process where the bulk material is pressed in a vessel or chamber that is placed under a universal compression testing machine. This vessel or chamber has holes that allows the leakage of oil (Herák et al., 2013; MunsonMcgee, 2014).

Information on the combined effect of the aforementioned pressing factors on the mechanical behaviour of bulk oil palm kernels under compression loading is limited. The present study seeks to remedy this by describing regression models of deformation, deformation energy and percentage oil yield of non-roasted bulk oil palm kernels depending on compressive force, compression speed and vessel diameter.

\section{MATERIALS AND METHOD}

Bulk oil palm kernels purchased from Afosu/Abirim in the Birim North District in the Eastern Region of Southern Ghana were used for the compression test. The moisture content of the samples was determined using the conventional method (ISI, 1996). From equation Eq. (1) (Blahovec, 2008), the moisture content was calculated to be 9.33 (\% w.b.):

$$
M C=\left(\frac{m_{a}-m_{b}}{m_{a}} 100\right),
$$

where: $M C$ is the percentage moisture content on a wet basis (\% w.b.), $m_{a}$ and $m_{b}$ are the masses of samples before and after oven drying at a temperature of $105^{\circ} \mathrm{C}$ and a drying time of $17 \mathrm{~h}$. A universal compression testing machine (ZDM 50, Czech Republic) and vessels of different diameters with a plunger were used. The initial height of the samples was measured at $60 \mathrm{~mm}$. Two different experiments were carried out. The first was done by varying the forces $\left(F_{m}, \mathrm{kN}\right)$ between 100 and $200 \mathrm{kN}$ and vessel diameters $(D, \mathrm{~mm})$ between 60 and $100 \mathrm{~mm}$ at a constant speed of $5 \mathrm{~mm} \mathrm{~min}{ }^{-1}$. The second test was done by varying the speeds $\left(R_{m}, \mathrm{~mm} \mathrm{~min}^{-1}\right)$ between 5 and $25 \mathrm{~mm} \mathrm{~min}^{-1}$ and vessel diameters $(D, \mathrm{~mm})$ at a constant force of $200 \mathrm{kN}$. All data were subjected to statistical analysis using multiple regression analysis employed in STATISTICA 13 software (Statsoft, 2013).

The percentage kernel oil yield was determined as the ratio of the mass of kernel oil (the difference between mass of initial height of kernels and mass of kernel cake) to that of the initial mass of bulk kernels (measured at an initial height of $60 \mathrm{~mm}$ ) multiplied by 100 - as given by Eq. (2) (Deli et al., 2011):

$$
O_{y}=\left(\frac{O_{w}}{O_{m}} 100\right),
$$

where: $O_{y}$ is the percentage kernel oil (\%), $O_{w}$ is the mass of kernel oil ( $\mathrm{g}$ ) and $O_{m}$ is the mass of initial pressing height of bulk kernels (g).

The volume of the bulk samples was determined using Eq. (3) (Chakespari et al., 2010; Herak et al., 2012):

$$
V=\left[\left(\frac{\pi D^{2}}{4}\right) H_{x}\right]
$$

where: $V$ is the volume of bulk kernels $\left(\mathrm{m}^{3}\right), D$ is the vessel diameter $(\mathrm{mm}), H_{x}$ is the initial height of bulk kernels $(\mathrm{mm})$. For all vessel diameters, the calculated volume values were $16.9710^{-5}, 30.1610^{-5}$ and $47.1310^{-5} \mathrm{~m}^{3}$, respectively.

The deformation energy of the bulk kernels was also calculated using Eq. (4) (Demirel et al., 2017; Herák et al., 2013 ; Kabutey et al., 2014):

$$
U=\sum_{n=0}^{n=i-1}\left[\left(\frac{F_{n+1}+F_{n}}{2}\right)\left(x_{n+1}-x_{n}\right)\right],
$$

where: $U$ is the deformation energy $(\mathrm{J}), F_{n+1}+F_{n}$ and $x_{n+1}-x_{n}$ are the compressive force $(\mathrm{N})$ and deformation $(\mathrm{mm}), n$ is the number of data points and $i$ is the number of sections in which the axis deformation was divided (step measurement was 0.5).

The volume energy, $u\left(\mathrm{~J} \mathrm{~m}^{-3}\right)$ of the bulk kernels was calculated using Eq. (5) (Chakespari et al., 2010; Gupta and Das, 2000; Łysiak, 2007):

$$
u=\frac{U}{V} .
$$

The hardness of the bulk kernels was calculated using Eq. (6) (Chakespari et al., 2010; Herak et al., 2012) which is the ratio of compressive force to that of the kernel maximum deformation:

$$
S_{x}=\frac{F_{m}}{D_{x}}
$$

where: $S_{x}$ is the bulk kernels hardness $\left(\mathrm{kN} \mathrm{mm}^{-1}\right), F_{m}$ is the compressive force $(\mathrm{kN})$ and $D_{x}$ is the bulk kernels maximum deformation ( $\mathrm{mm}$ ).

\section{RESULTS AND DISCUSSION}

The results of the study are presented in Tables 1 to 5 and Figs 1 and 2, respectively. For varying forces and vessel diameters at a constant speed of $5 \mathrm{~mm} \mathrm{~min}^{-1}$, the aforementioned parameters also ranged from $28.47 \pm 0.89$ to $37.45 \pm 0.11 \mathrm{~mm}, 796 \pm 0.82$ to $1795 \pm 49.01 \mathrm{~J}$ and $7.33 \pm 0.26$ to $25.67 \pm 0.39 \%$ (Table 1 ). The deformation decreased with increased vessel diameters, but increased with compression force increase. The deformation energy increased 
Table 1. Deformation, deformation energy and oil yield of non-roasted bulk oil palm kernels at varying forces and vessel diameters

\begin{tabular}{|c|c|c|c|c|}
\hline \multicolumn{2}{|c|}{ Level of factors } & \multicolumn{3}{|c|}{ Mean \pm standard deviation of measured amounts } \\
\hline $\begin{array}{c}\text { Forces } \\
(\mathrm{kN})\end{array}$ & $\begin{array}{l}\text { Vessel diameters } \\
D(\mathrm{~mm})\end{array}$ & $\begin{array}{c}\text { Deformation } \\
D_{x}\left(10^{-3} \mathrm{~m}\right)\end{array}$ & $\begin{array}{c}\text { Deformation energy } \\
U(\mathrm{~J})\end{array}$ & $\begin{array}{l}\text { Oil yield } \\
O_{y}(\%)\end{array}$ \\
\hline \multirow{3}{*}{100} & 60 & $35.67 \pm 0.21$ & $796 \pm 0.82$ & $22.16 \pm 1.04$ \\
\hline & 80 & $32.88 \pm 2.09$ & $991 \pm 29.46$ & $14.67 \pm 0.91$ \\
\hline & 100 & $28.47 \pm 0.89$ & $1019 \pm 27.71$ & $7.33 \pm 0.26$ \\
\hline \multirow{3}{*}{125} & 60 & $36.91 \pm 0.83$ & $871 \pm 53.84$ & $22.99 \pm 1.44$ \\
\hline & 80 & $33.25 \pm 2.19$ & $1079 \pm 73.37$ & $15.08 \pm 2.06$ \\
\hline & 100 & $31.37 \pm 0.49$ & $1340 \pm 12.09$ & $11.90 \pm 0.51$ \\
\hline \multirow{3}{*}{150} & 60 & $36.65 \pm 0.51$ & $912 \pm 46.44$ & $23.73 \pm 1.44$ \\
\hline & 80 & $34.66 \pm 1.56$ & $1243 \pm 28.69$ & $17.59 \pm 0.91$ \\
\hline & 100 & $32.41 \pm 0.15$ & $1541 \pm 41.51$ & $15.07 \pm 0.21$ \\
\hline \multirow{3}{*}{175} & 60 & $36.62 \pm 1.11$ & $1007 \pm 15.10$ & $25.30 \pm 0.13$ \\
\hline & 80 & $34.62 \pm 0.74$ & $1353 \pm 57.77$ & $19.46 \pm 1.23$ \\
\hline & 100 & $34.31 \pm 1.28$ & $1673 \pm 43.19$ & $16.16 \pm 0.37$ \\
\hline \multirow{3}{*}{200} & 60 & $37.45 \pm 0.11$ & $1094 \pm 4.13$ & $25.67 \pm 0.39$ \\
\hline & 80 & $35.23 \pm 0.57$ & $1408 \pm 43.33$ & $19.36 \pm 0.00$ \\
\hline & 100 & $34.72 \pm 0.45$ & $1795 \pm 49.01$ & $17.51 \pm 0.09$ \\
\hline
\end{tabular}

At a constant speed of $5 \mathrm{~mm} \mathrm{~min}^{-1}$.

Ta b le 2. Deformation, deformation energy and oil yield of non-roasted bulk oil palm kernels at different speeds and vessel diameters

\begin{tabular}{|c|c|c|c|c|}
\hline \multicolumn{2}{|c|}{ Level of factors } & \multicolumn{3}{|c|}{ Mean \pm standard deviation of measured amounts } \\
\hline $\begin{array}{c}\text { Speeds } \\
R_{m}\left(\mathrm{~mm} \mathrm{~min}^{-1}\right)\end{array}$ & $\begin{array}{c}\text { Vessel diameters } \\
D(\mathrm{~mm})\end{array}$ & $\begin{array}{c}\text { Deformation } \\
D_{x}\left(10^{-3} \mathrm{~m}\right)\end{array}$ & $\begin{array}{c}\text { Deformation energy } \\
U(\mathrm{~J})\end{array}$ & $\begin{array}{l}\text { Oil yield } \\
O_{y}(\%)\end{array}$ \\
\hline \multirow{3}{*}{5} & 60 & $37.37 \pm 0.00$ & $1081 \pm 22.38$ & $24.98 \pm 1.37$ \\
\hline & 80 & $35.79 \pm 0.22$ & $1420 \pm 27.38$ & $18.10 \pm 1.77$ \\
\hline & 100 & $34.98 \pm 0.08$ & $1795 \pm 63.86$ & $17.33 \pm 0.35$ \\
\hline \multirow{3}{*}{10} & 60 & $37.63 \pm 1.21$ & $1078 \pm 14.26$ & $24.19 \pm 0.52$ \\
\hline & 80 & $35.48 \pm 1.04$ & $1345 \pm 10.89$ & $17.84 \pm 0.04$ \\
\hline & 100 & $31.91 \pm 1.61$ & $1720 \pm 15.69$ & $16.49 \pm 0.37$ \\
\hline \multirow{3}{*}{15} & 60 & $36.75 \pm 0.71$ & $1026 \pm 3.36$ & $22.85 \pm 0.21$ \\
\hline & 80 & $34.62 \pm 2.45$ & $1357 \pm 43.18$ & $17.18 \pm 0.91$ \\
\hline & 100 & $33.84 \pm 0.27$ & $1780 \pm 68.98$ & $15.59 \pm 0.72$ \\
\hline \multirow{3}{*}{20} & 60 & $36.38 \pm 0.48$ & $1012 \pm 26.76$ & $22.31 \pm 0.72$ \\
\hline & 80 & $34.25 \pm 0.18$ & $1357 \pm 15.75$ & $16.82 \pm 0.76$ \\
\hline & 100 & $33.09 \pm 1.13$ & $1686 \pm 14.05$ & $15.08 \pm 0.60$ \\
\hline \multirow{3}{*}{25} & 60 & $36.96 \pm 0.78$ & $1017 \pm 16.91$ & $19.99 \pm 0.72$ \\
\hline & 80 & $34.31 \pm 1.05$ & $1344 \pm 1.07$ & $15.18 \pm 0.33$ \\
\hline & 100 & $32.86 \pm 0.31$ & $1717 \pm 2.92$ & $14.66 \pm 0.42$ \\
\hline
\end{tabular}

At a constant force of $200 \mathrm{kN}$. 
Table 3. Repeated measured ANOVA statistical analysis of measured amounts of non-roasted bulk oil palm kernels

\begin{tabular}{|c|c|c|c|c|}
\hline \multicolumn{5}{|c|}{ Forces and vessel diameters at a constant speed of $5 \mathrm{~mm} \mathrm{~min}^{-1}$} \\
\hline Measured variables & $\mathrm{R}^{2}$ & F-ratio & F-critical & p-value \\
\hline Deformation (mm) & 0.78 & 47.03 & & $<0.05$ \\
\hline Deformation energy $(\mathrm{J})$ & 0.92 & 156.6 & 2.64 & $<0.05$ \\
\hline Kernel oil yield (\%) & 0.91 & 134.4 & & $<0.05$ \\
\hline \multicolumn{5}{|c|}{ Speeds and vessel diameters at a constant force of $200 \mathrm{kN}$} \\
\hline Deformation (mm) & 0.74 & 37.73 & & $<0.05$ \\
\hline Deformation energy $(\mathrm{J})$ & 0.99 & 979.8 & 2.64 & $<0.05$ \\
\hline Kernel oil yield (\%) & 0.85 & 76.39 & & $<0.05$ \\
\hline
\end{tabular}

Significant $\left(\mathrm{p}<0.05\right.$ or $\left.\mathrm{F}_{\text {ratio }}>\mathrm{F}_{\text {critical }}\right)$. F-ratio is the value of the $\mathrm{F}$ test $(-)$, F-critical is the critical value that compares a pair of models $(-)$, p-value is the significance level used for testing a statistical hypothesis $(-), \mathrm{R}^{2}$ is the coefficient of determination (-).

with both the vessel diameter increase and compression force increase. The percentage kernel oil decreased with increased vessel diameter, but increased with compression force increase. The linear regression models describing the dependence of deformation, deformation energy and kernel oil yield on force $\left(F_{m}, \mathrm{kN}\right)$ and vessel diameter $(D, \mathrm{~mm})$ are given in Eqs (7), (8) and (9) as follows:

$$
\begin{gathered}
D_{x}=-0.11 D+0.03 F_{m}+38.21, \\
U=13.44 D+4.97 F_{m}-612.4, \\
O_{y}=-0.26 D+0.06 F_{m}+29.42 .
\end{gathered}
$$

In contrast, for different speeds and vessel diameters at a constant force of $200 \mathrm{kN}$; the values of deformation, deformation energy and kernel oil yield ranged from $31.91 \pm 1.61$ to $37.63 \pm 1.21 \mathrm{~mm}, 1012 \pm 26.76$ to $1795 \pm 49.01$ $\mathrm{J}$ and $14.66 \pm 0.42$ to $24.98 \pm 1.37 \%$ (Table 2). The deformation and percentage kernel oil decreased along with both speed increase and vessel diameter increase, while the deformation energy decreased with increasing speeds but increased with vessel diameter increase. The linear regression relationships explaining the function of deformation, deformation energy and kernel oil yield on speed $\left(R_{m}, \mathrm{~mm}\right.$ $\left.\mathrm{min}^{-1}\right)$ and vessel diameter $(D, \mathrm{~mm})$ are shown in Eqs $(10)$, (11) and (12) as follows:

$$
\begin{gathered}
D_{x}=-0.09 D-0.06 R_{m}+43.37, \\
U=17.37 D-3.35 R_{m}+42.52, \\
O_{y}=-0.18 D-0.17 R_{m}+35.19 .
\end{gathered}
$$

The determined parameters were statistically significant $(\mathrm{p}<0.05)$ or $($ F-ratio $>$ F-critical $)$ with the coefficients of determination $\left(\mathrm{R}^{2}\right)$ between 0.74 and 0.99 (Table 3). This means that the varying pressing factors: speed, force and vessel diameter being the independent variables under

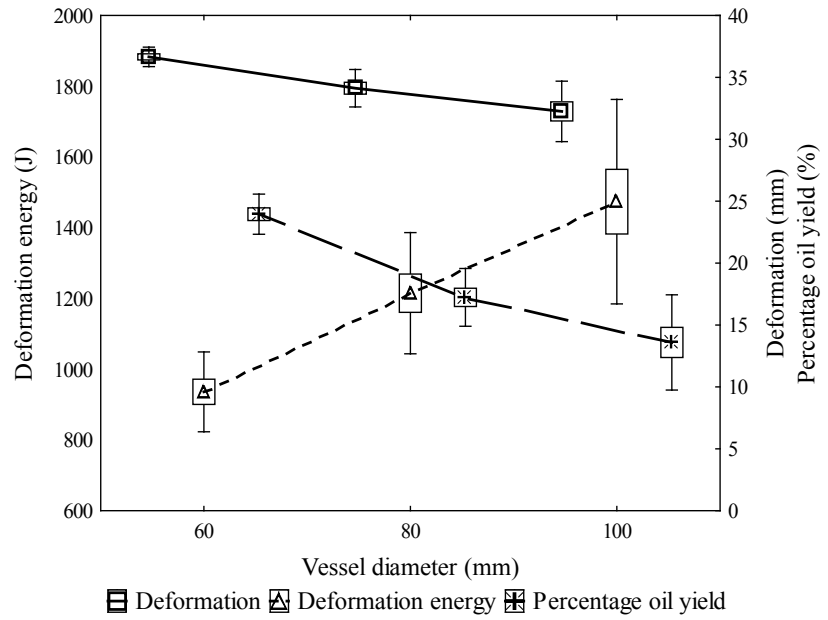

Fig. 1. Box plot of deformation, deformation energy and percentage oil yield versus vessel diameter.

consideration, influenced the dependent variables, namely, the deformation, deformation energy and kernel oil yield. Figure 1 shows the box plot of the dependencies of deformation, deformation energy and percentage kernel oil versus vessel diameter.

The volume energy and hardness are given in Tables 4 and 5 . These parameters were not specifically dependent as described in Eqs (5) and (6), and the varying speeds had no significant effect. Contrarily, volume energy significantly decreased with increasing vessel diameters, while hardness increased. Furthermore, the volume energy increased along with the compression forces, while it decreased with the vessel diameter increase. The hardness, however, increased with increasing compression forces and increasing vessel diameters, respectively. We also observed that the kernels after compression did not achieve permanent deformation in relation to the applied loads and speeds. This suggests that more kernel oil could be obtained at a force greater than $200 \mathrm{kN}$. Generally, the volume energy and hardness represent the toughness or rigidity of the bulk material (Chakespari et al., 2010; Łysiak, 2007; Gupta and Das, 2000). 
Table 4. Hardness and volume energy of non-roasted bulk kernels at varying forces and vessel diameters

\begin{tabular}{|c|c|c|c|}
\hline $\begin{array}{l}\text { Forces } \\
D(\mathrm{kN})\end{array}$ & $\begin{array}{c}\text { Vessel } \\
\text { diameters } \\
D(\mathrm{~mm})\end{array}$ & $\begin{array}{c}\text { Volume } \\
\text { energy } \\
u\left(10^{6} \mathrm{~J} \mathrm{~m}^{-3}\right)\end{array}$ & $\begin{array}{c}\text { Hardness } \\
S_{x}\left(\mathrm{kN} \mathrm{mm}^{-1}\right)\end{array}$ \\
\hline \multirow{3}{*}{100} & 60 & $4.69 \pm 0.05$ & $2.80 \pm 0.02$ \\
\hline & 80 & $3.29 \pm 0.11$ & $3.05 \pm 0.19$ \\
\hline & 100 & $2.16 \pm 0.06$ & $3.51 \pm 0.11$ \\
\hline \multirow{3}{*}{125} & 60 & $5.14 \pm 0.32$ & $3.39 \pm 0.08$ \\
\hline & 80 & $3.58 \pm 0.24$ & $3.77 \pm 0.25$ \\
\hline & 100 & $2.84 \pm 0.03$ & $3.99 \pm 0.06$ \\
\hline \multirow{3}{*}{150} & 60 & $5.38 \pm 0.27$ & $4.09 \pm 0.06$ \\
\hline & 80 & $4.12 \pm 0.11$ & $4.33 \pm 0.19$ \\
\hline & 100 & $3.27 \pm 0.09$ & $4.63 \pm 0.02$ \\
\hline \multirow{3}{*}{175} & 60 & $5.93 \pm 0.09$ & $4.78 \pm 0.15$ \\
\hline & 80 & $4.49 \pm 0.10$ & $5.06 \pm 0.11$ \\
\hline & 100 & $3.55 \pm 0.09$ & $5.11 \pm 0.19$ \\
\hline \multirow{3}{*}{200} & 60 & $6.45 \pm 0.02$ & $5.34 \pm 0.02$ \\
\hline & 80 & $4.67 \pm 0.10$ & $5.68 \pm 0.09$ \\
\hline & 100 & $3.81 \pm 0.10$ & $5.76 \pm 0.08$ \\
\hline
\end{tabular}

At a constant speed of $5 \mathrm{~mm} \mathrm{~min}^{-1}$.
Table 5. Hardness and volume energy of non-roasted bulk kernels at varying speeds and vessel diameters

\begin{tabular}{|c|c|c|c|}
\hline $\begin{array}{c}\text { Speeds } \\
R_{m} \\
\left(\mathrm{~mm} \mathrm{~min}^{-1}\right)\end{array}$ & $\begin{array}{c}\text { Vessel } \\
\text { diameters } \\
D(\mathrm{~mm})\end{array}$ & $\begin{array}{l}\text { Volume energy } \\
u\left(10^{6} \mathrm{~J} \mathrm{~m}^{-3}\right)\end{array}$ & $\begin{array}{c}\text { Hardness } \\
S_{x}\left(\mathrm{kN} \mathrm{mm}^{-1}\right)\end{array}$ \\
\hline \multirow{3}{*}{5} & 60 & $6.45 \pm 0.02$ & $5.34 \pm 0.02$ \\
\hline & 80 & $4.67 \pm 0.14$ & $5.68 \pm 0.09$ \\
\hline & 100 & $3.81 \pm 0.10$ & $5.76 \pm 0.08$ \\
\hline \multirow{4}{*}{10} & 60 & $6.36 \pm 0.08$ & $5.32 \pm 0.17$ \\
\hline & 80 & $4.46 \pm 0.04$ & $5.64 \pm 0.17$ \\
\hline & 100 & $3.65 \pm 0.03$ & $6.28 \pm 0.31$ \\
\hline & 60 & $6.05 \pm 0.02$ & $5.44 \pm 0.11$ \\
\hline \multirow[t]{2}{*}{15} & 80 & $4.51 \pm 0.14$ & $5.79 \pm 0.41$ \\
\hline & 100 & $3.78 \pm 0.15$ & $5.91 \pm 0.05$ \\
\hline \multirow{3}{*}{20} & 60 & $5.96 \pm 0.16$ & $5.49 \pm 0.07$ \\
\hline & 80 & $4.50 \pm 0.05$ & $5.84 \pm 0.03$ \\
\hline & 100 & $3.58 \pm 0.03$ & $6.05 \pm 0.21$ \\
\hline \multirow{3}{*}{25} & 60 & $5.99 \pm 0.10$ & $5.41 \pm 0.11$ \\
\hline & 80 & $4.46 \pm 0.00$ & $5.83 \pm 0.18$ \\
\hline & 100 & $3.64 \pm 0.01$ & $6.09 \pm 0.06$ \\
\hline
\end{tabular}

At a constant force of $200 \mathrm{kN}$.

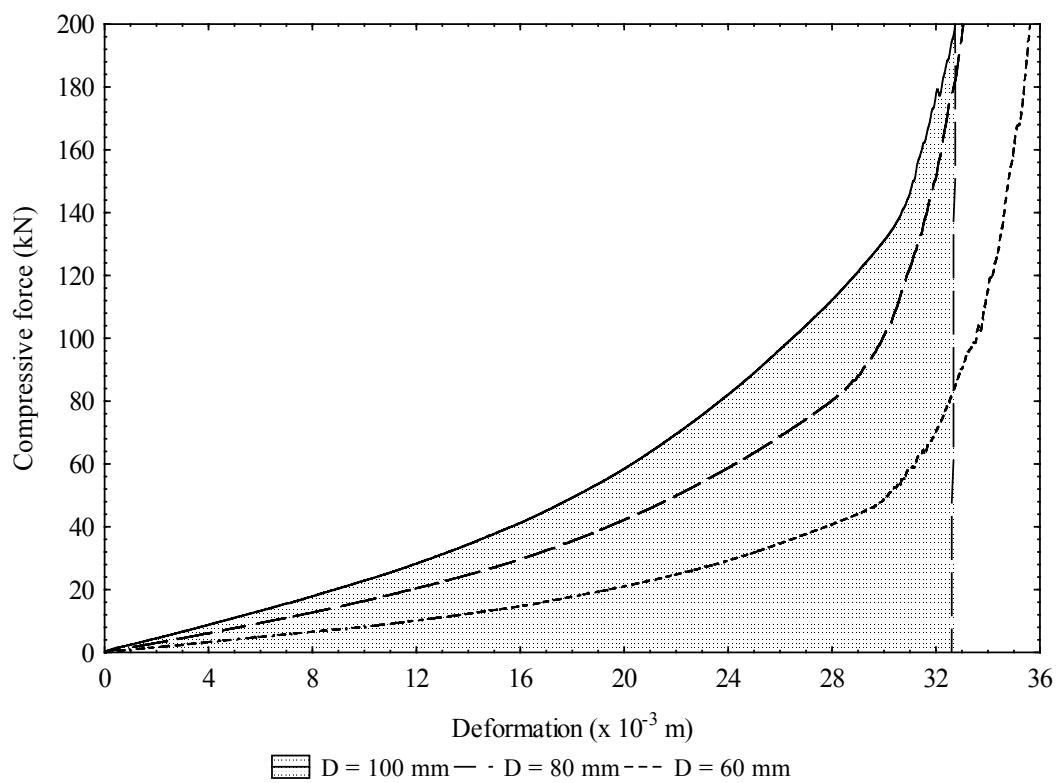

Fig. 2. Dependency between compressive force and deformation curves of non-roasted bulk oil palm kernels in relation to the vessel diameters $(D)$.

The force-deformation curves from the compression test of non-roasted bulk oil palm kernels are illustrated in Fig. 2. The area under the curve represents the deformation energy (Lysiak, 2007; Gupta and Das, 2000) required for obtaining the kernel oil. In the literature, the force-defor- mation characteristic curve can also be employed to assess the damage during harvesting and handling of grains, seeds, fruits and vegetables, as well as other food products (Raji and Favier, 2004; Stroshine, 1998). 
In a broader perspective, the results presented here are related to the findings of Deli et al. (2011) who compared pressure and oil yield of Nigella sativa L. seeds in response to two screw shafts of diameter 8 and $11 \mathrm{~mm}$. The authors indicated that the pressure towards the seeds in the smaller shaft increased, resulting in higher percentage of oil recovered, while the bigger space provided by the bigger shaft needed a higher speed to give optimum pressure towards the seeds in order to achieve maximum oil yield.

Other studies (Beerens, 2007; Karaj and Muller, 2011) also indicated that lower energy input results in higher oil residue in seed-cake and higher material throughput since less time is available for oil leakage from the solids. Karaj and Muller (2011), also reported that the speed influences the energy and the processing time necessary for obtaining the maximum amount of oil. In addition, the viscosity thus remains lower at a higher speed resulting in less pressure and more oil content in press cake. In oil extraction involving the mechanical screw press, the general hypothesis is that higher pressure will result in higher temperature generation and higher oil recovery efficiency (Willems et al., 2008; 2009). For optimizing the mechanical screw press, the pressing factors: force or pressure, speed and diameter of pressing chamber (among others) are important for consideration in compression loading experiments.

\section{CONCLUSIONS}

1. Linear regression models were described for nonroasted bulk oil palm kernels deformation, deformation energy and percentage kernel oil yield depending on speed, force and vessel diameter.

2 . The models were statistically significant $(\mathrm{p}<0.05)$ or (F-ratio $>$ F-critical), with high coefficients of determination between 0.74 and 0.99 .

3. Higher percentage kernel oil was observed with the vessel diameter of $60 \mathrm{~mm}$ than the vessel diameters of 80 and $100 \mathrm{~mm}$.

4. Percentage kernel oil yield decreased with the increase in speed.

5. For all the vessel diameters, at a maximum compressive force of $200 \mathrm{kN}$ and a minimum speed of $5 \mathrm{~mm} \mathrm{~min}^{-1}$, the bulk oil palm kernels did not achieve permanent deformation. This indicates the presence of oil residue in the kernels which might require a much greater force and/or a lower speed to recover.

Conflict of interest: The Authors do not declare conflict of interest.

\section{REFERENCES}

Akinoso R. and Raji A.O., 2011. Physical properties of fruit, nut and kernel of oil palm. Int. Agrophys., 25, 85-88.

Akinoso R., Raji A.O., and Igbeka J.C., 2009. Effects of compressive stress, feeding rate and speed on palm kernel oil yield. J. Food Eng., 93, 427-430.
Aripin N.F.K., Park J.W., and Park H.J., 2012. Preparation of vesicle drug carrier from palm-oil and kernel oil-based glycosides. Colloids and Surfaces B: Biointerfaces. 95, 144-153.

Beerens P., 2007. Screw-pressing of Jatropha seeds for fuelling purposes in less developed countries. MSc. Thesis, Department of Sustainable Energy Technology, Eindhoven University of Technology, The Netherlands.

Blahovec J., 2008. Agromaterials Study Guide. Czech University of Life Sciences Prague, Prague, Czech Republic.

Chakespari A.G., Rajabipour A., and Mobli H., 2010. Strength behaviour study of apples (cv. Shaft Abadi and Golab Kohanz) under compression loading. Modern Appl. Sci., 4(7), 173-182.

Deli S., Farah Masturah M., TajuL Aris Y., and Wan Nadiah W.A., 2011. The effects of physical parameters of the screw press oil expeller on oil yield from Nigella sativa L. seeds. J. Int. Food Res., 18(4), 1367-1373.

Demirel C., Kabutey A., Herak D., and Gurdil G.A.K. 2017. Numerical estimation of deformation energy of selected bulk oilseeds in compression loading. IOP Conf. Series: Materials Sci. Eng., 237(1), 1-5.

Divišová M., Herák D., Kabutey A., Sigalingging R., and Svatoňová T., 2014. Deformation curve characteristics of rapeseeds and sunflower seeds under compression loading. Scientia Agriculturae Bohemica, 45(3), 180-186.

Galedar M.N., Mohtasebi S.S., Tabatabaeefar A., Jafari A., and Fadaei H., 2009. Mechanical behaviour of pistachio nut and its kernel under compression loading. J. Food Eng., 95, 499-504.

Gupta R.K. and Das S.K., 2000. Fracture resistance of sunflower seed and kernel to compressive loading. Food Eng., 46, 1-8.

Herak D., Gurdil G., Sedlacek A., Dajbych O., and Simanjuntak S., 2010. Energy demands for pressing Jatropha curcas L. seeds. Biosystems Eng., 106, 527-534.

Herák D., Kabutey A., Divišová M., and Simanjuntak S., 2013. Mathematical model of mechanical behaviour of Jatropha curcas L. seeds under compression loading. Biosystems Eng., 114(3), 279-288.

Herak D., Kabutey A., Sedláček A., and Gurdil G., 2012. Mechanical behaviour of several layers of selected plant seeds under compression loading. Res. Agric. Eng., 58, 24-29.

ISI, 1966. Indian standard methods for analysis of oilseeds, IS: 3579. New Delhi, Indian Standard Institute.

Kabutey A., Herák D., Chotěborský R., Dajbych O., Divišova M., and Boatri W.E., 2013. Linear pressing analysis of Jatropha curcas L. bulk seeds using different pressing vessel diameters and seed pressing heights. Biosys. Eng., 115, 43-49.

Kabutey A., Herák D., Chotěborský R., Sigalingging R., and Mizera Č., 2015. Effect of compression speed on energy requirement and oil yield of Jatropha curcas L. bulk seeds under linear compression. Biosys. Eng., 136, 8-13.

Kabutey A., Herák D., Dajbych O., Divišová M., Boatri W.E., and Sigalingging R., 2014. Deformation energy of Jatropha curcas L. seeds under compression loading. Res. Agric. Eng., 60, 68-74.

Karaj S. and Muller J., 2010. Determination of physical, mechanical and chemical properties of seeds and kernels of Jatropha curcas L. Industrial Crops and Products, 32, 129-138. 
Karaj S. and Muller J., 2011. Optimizing mechanical oil extraction of Jatropha curcas L. seeds with respect to press capacity, oil recovery and energy efficiency. Industrial Crops and Products, 34, 1010-1016.

Łysiak G., 2007. Fracture toughness of pea: Weibull analysis. J. Food Eng., 83, 436-443.

Munson-Mcgee S.H., 2014. D-optimal experimental designs for uniaxial expression. J. Food Process Eng., 37, 248-256.

Ozumba I.C. and Obiakor S.I., 2011. Fracture resistance of palm kernel seed to compressive loading. J. Stored Products Postharvest Res., 2(13), 248-253.

Raji A.O. and Favier J.F., 2004. Model for the deformation in agricultural and food particulate materials under bulk compressive loading using discrete element method II: theory, compression of oilseeds. J. Food Eng., 64(3), 373-380.

Sigalingging R., Herák D., Kabutey A., Čestmír M., and Divišová M., 2014. Tangent curve function description of mechanical behaviour of bulk oilseeds: A review. Scientia Agriculturae Bohemica, 45(4), 259-264.

Sigalingging R., Herák D., Kabutey A., Dajbych O., Hrabě P., and Mizera $\check{C}$., 2015. Application of a tangent curve mathematical model for analysis of the mechanical behaviour of sunflower bulk seeds. Int. Agrophys., 29, 517-524.
Sirisomboon P., Kitchaiya P., Pholpho T., and Mahuttanyavanitch T., 2007. Physical and mechanical properties of Jatropha curcas L. fruits, nuts and kernels. Biosys. Eng., 97(2), 201-207.

Statsoft, 2013. Inc. Tulsa, OK74104, USA.

Stroshine R., 1998. Physical properties of agricultural materials and food products. Department of Agricultural and Biological Engineering, Pardue University, West Lafayette, IN, USA.

Tunde-Akintunde T.Y., Akintunde B.O., and Igbeka J.C., 2001. Effects of processing factors on yield and quality of mechanically expressed soybean oil. J. Eng. Technol., 1, 39-45.

Willems P., Kuipers N.J.M., and De Haan A.B., 2008. Hydraulic pressing of oilseeds: experimental determination and modeling of yield and pressing rates. J. Food Eng., 89, 8-16.

Willems P., Kuipers N.J.M., and De Haan A.B., 2009. A consolidation based extruder model to explore GAME process configurations. J. Food Eng., 90, 238-245.

Zheng Y., Wiesenborn D.P., Tostenson K., and Kangas N., 2003. Screw pressing of whole and dehulled flaxseed for organic oil. J. Am. Oil Chemistry Soc., 80, 1039-1045. 